\title{
Direct Pulp Capping with Calcium-Based Materials: A Mini-Review
}

\section{ISSN: 2637-7764}

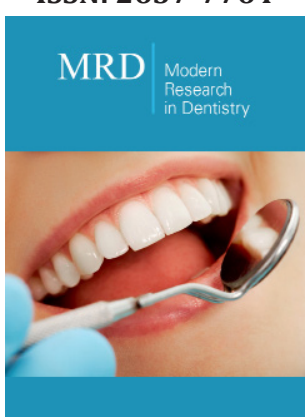

*Corresponding author: Maria Stella Moreira, Pos-Graduation Dentistry Program, Ibirapuera University

Av. Interlagos, 1329-4o -Chácara Flora, ZIP code: 04661-100, São Paulo-SP, Brazil

Submission: 眥 February 15, 2021

Published: 制April 05, 2021

Volume 6 - Issue 2

How to cite this article: Giovanna Sarra, Maria Stella Moreira, Giovanna Lopes Carvalho, Hector Valentin CaballeroFlores, et al. Direct Pulp Capping with Calcium-Based Materials: A Mini-Review. Mod Res Dent. 6(2). MRD. 000632. 2021. DOI:_10.31031/MRD.2021.06.000632

Copyright@ Maria Stella Moreira, This article is distributed under the terms of the Creative Commons Attribution 4.0 International License, which permits unrestricted use and redistribution provided that the original author and source are credited.
Giovanna Sarra ${ }^{1}$, Maria Stella Moreira ${ }^{2,3 *}$, Giovanna Lopes Carvalho ${ }^{2}$, Hector Valentin Caballero-Flores ${ }^{1}$, Márcia Martins Marques $^{3}$ and Manoel Eduardo de Lima Machado ${ }^{1}$

${ }^{1}$ Department of Restorative Dentistry, School of Dentistry, Universidade de São Paulo, São Paulo, Brazil

${ }^{2}$ A.C. Camargo Cancer Center, Stomatology Department, São Paulo, Brazil

${ }^{3}$ Post-Graduation Program in Dentistry, School of Dentistry, Ibirapuera University, São Paulo, Brazil

\begin{abstract}
The dentin-pulp complex responds to injuries and harmful stimuli that affect the tooth by depositing dentin matrix in order to protect the pulp tissue, maintaining tooth vitality. However, maintaining vitality after pulp tissue exposure is still a challenge in dentistry. In this sense, the re-emergence of vital pulp therapies gained strength, especially due to its biologically minimally invasive approach. Among them, direct pulp capping is considered a low invasive technique based on the placement of a dental material directly on the exposed pulp site, facilitating the formation of a protective barrier and the maintenance of pulp vitality. Calcium hydroxide was the most used material for this purpose in the last decades. However, the development of new biocompatible materials, such as MTA and Biodentine, has being related with higher rates of clinical and radiographic success, reinforcing the effectiveness of this treatment. Despite that, more randomized clinical trials and histomorphological analysis of the newformed hard tissue are still needed to assess the quality of this treatment in the long term.
\end{abstract}

\section{Introduction}

The dentin-pulp complex is a biological complex composed by dentin and pulp tissues, which maintains an intimate structural, embryological and functional relationship. In this way, dentin and pulp are not considered isolated structures, but rather a complex in which tissue response mechanisms and its repercussions act as an integrated manner, maintaining a profound relationship throughout the life of the tooth. While the dental pulp has the essential function of forming the dentin matrix, the dentin, in turn, protects the pulp from external stimuli, coating it with a hard mineralized tissue [1-3].

The dentin-pulp complex vitality throughout a tooth's life contrasts with the loss of cellular enamel material after its eruption in the oral cavity. As an important consequence of this vitality, the dentin-pulp complex is able to respond to injuries and harmful stimuli that affect the tooth. When dentin is physically and/or chemically attacked, the pulp responds to these stimuli aiming to decrease dentin permeability through the formation of dentin matrix, as long as this tissue is not contaminated by bacteria and these stimuli do not exceed its repair capacity. The nature and magnitude of the response will reflect the extent of the lesion and the condition of the tissue in the complex [4-6].

The relationship between dentin and pulp starts in the tooth germ, when the first layers of dentin are deposited by odontoblasts that are recently differentiated from the dental papilla. Odontoblasts are post-mitotic cells organized as a layer of palisade cells along the interface between dental pulp and dentin [7]. Primary (developmental) dentin is formed by these cells during tooth development. In post-development, odontoblasts continue to deposit secondary (physiological) dentin slowly over the tooth lifetime [7,8] (Orchadson 2001). Tertiary dentin, in turn, is deposited in response to an injury or damage to dental tissues. It differs from the primary and secondary not only in its deposition rate, but also in its composition [9].

Several injuries can cause damage to the dentin-pulp complex. Among them, we can highlight the restorative procedures (cavity preparations and materials applied to the dentin), caries lesions and dental wear or trauma. In general, these stimuli can occur in small or large 
extent and in low or high intensity, reflecting significantly on the type of tertiary dentin to be formed $[10,11]$.

In this way, tertiary dentin can be subclassified as reactive or reparative. The reactive dentinal matrix is deposited by surviving odontoblasts that regulate its secretory activity in response to a relatively mild stimulus (of small extension and low intensity). In turn, the reparative dentin is secreted by a new generation of cells (odontoblast-like cells) differentiated from populations of progenitor stem cells. This process occurs in response to a stimulus of greater extension and intensity, culminating in the death of primary odontoblasts $[11,12]$. This process is more complex, since it requires initial recruitment of progenitor cells, signaling of cell differentiation and secretion of dentinal matrix $[13,14]$.

After the recruitment and migration of stem and progenitor cells to the injury site, these cells begin to proliferate, expand, and then differentiate into odontoblast-like cells, under the influence of bioactive molecule signaling [15]. The odontoblastic cells synthesize organic matrix of type I and type $\mathrm{V}$ collagen and actively participate in its mineralization by secreting proteoglycans, glycoproteins and non-collagen proteins involved in nucleation and in the control of the growth of the mineral phase, such as: sialophosphoprotein dentin sialophosphoprotein), dentin matrix protein 1 (DMP-1, from dentin matrix protein1), alkaline phosphatase (ALP from English alkaline phosphatase) and osteocalcin (BGLAP from English bone gamma-carboxyglutamic acid-containing protein). All these components of the organic dentinal matrix will subsequently be mineralized, forming a reparative hard tissue $[2,7]$.

The inflammatory process, caused by pulp injury, is responsible for inducing the repair process. The dentin-pulp complex reacts to the harmful stimulus through a combination of inflammation and mineralization. The balance between pulpitis and repair is essential to preserve pulp vitality. Thus, both processes must be in balance for the repair to take place. Otherwise, if the inflammatory response happens too intensely, the effects on the pulp tissue will be harmful, hindering the repair process and possibly leading to cell death. In cases of pulp tissue infection, the problem becomes even more serious. There will then be a need for balance between the inflammatory and repair processes, in order to favor the recovery of pulp tissue $[9,16,17]$.

Traditionally, the management of deep carious lesions has been conducted with complete (or non-selective) removal of carious tissue, which can often lead to unintended pulp exposure and, consequently, endodontic treatment. However, management strategies for treating moderately exposed pulp have been changing in recent years. There is a resurgence of a tendency to avoid pulpectomy and return to vital pulp treatment techniques, such as partial or complete pulpotomy and direct pulp capping. These changes results of a better understanding of the repairing response of the dentin-pulp complex [18].

The success of restorative dentinogenesis depends on the adequate reestablishment of the morpho functional integrity of the dentin-pulp complex, making it capable of forming dentinal tissue in the site adjacent to the lesion, with a controlled inflammatory response. For this, the protection of the dentin-pulp complex through the application of specific materials between the pulp tissue and the restorative material can avoid additional damage caused by the surgical procedure, toxicity of the restorative materials and penetration of microorganisms due to infiltration [19-21].

The last few years have been marked by the development of new materials for this purpose, resulting in more predictable treatments from a clinical point of view. However, scientific evidence is still not consistent in relation to critical issues such as the prognosis of treatments, superiority between the materials used and quality of the newly formed bridge and underlying pulp tissue [18].

\section{Direct Pulp Capping}

Among the several trends in contemporary endodontics, we can highlight the development of biologically minimally invasive therapies, including the regenerative endodontic procedures and vital pulp therapy. Direct pulp capping is a less invasive approach to keep the exposed pulp vital [22].

As highlighted previously, the exposure of the pulp tissue places at risk the maintenance of the vitality of the dentin-pulp complex. This loss of vitality is even more serious when it affects teeth with incomplete rhizogenesis, where the development of the dental root is interrupted, resulting in tooth with shorter roots and thinner dentinal walls, which can lead to root fracture and loss of the element [23].

In general, there are three main causes for vital pulp exposure: caries injuries, mechanical factors and trauma. Caries exposure occurs when the carious lesion advances sufficiently towards the pulp tissue, exposing it even before the complete removal of the carious tissue. On the other hand, if exposure occurs during the preparation of a cavity free of caries, this is considered a mechanical exposure. This type of exposure usually occurs accidentally during tooth preparation. Traumatic exposure, in turn, is the result of trauma (such as during sports) capable of fracturing the coronal part of the tooth [24].

Treatment options for pulp exposure are pulpectomy followed by endodontic treatment, pulpotomy (partial or complete) and direct pulp capping.

Among them, direct pulp capping is considered the least invasive technique and is based on the placement of a dental material directly on the exposed pulp area in order to facilitate both the formation of a protective barrier [25-27] regarding the maintenance of pulp vitality $[28,29]$.

Several factors can directly affect the results of direct pulp capping treatment. Among them, the patient's age and the clinical condition of the pulp related to the patient's symptoms are of importance. Younger patients tend to respond with a higher success rate than older patients $[30,31]$. This factor is probably related to the high metabolic rate and repair capacity of the youngest pulp. In addition, in general, the vital pulp can be classified into three clinical conditions: normal pulp, reversible pulpitis or irreversible pulpitis. Pulp capping is indicated in cases of normal pulp or 
reversible pulpitis, when the patient has no clinical symptoms or when the symptoms disappear after the removal of the harmful stimulus [24].

The first direct pulp capping treatment was carried out in 1756 by Pfaff, using gold leaf [24]. Since then, several materials have been recommended for direct pulp capping [32,33]. Pulp capping materials are dental materials used to protect the exposed dentinpulp complex and must promote pulp repair without causing damage to cells and the extracellular matrix, in order to maintain specialized connective tissue with normal characteristics, as well as promote the formation of dentin tissue $[1,34]$.

Some properties are desired and considered essential for an ideal capping material, such as: ability to control infection; controlling inflammation; present adhesion to dentin, preventing infiltration; be easy to handle; promote the formation of dentin tissue; be biocompatible; and to be a biostimulator, which means to be able to modulate the pulp tissue response to aggression $[17,35,36]$.

Currently, there are several materials available to be used in capping procedures. Among them, the most used and described in the literature are Calcium Hydroxide $(\mathrm{CH})$, Mineral Trioxide Aggregate (MTA) and, more recently, tricalcium silicate-based material (Bio dentine) [24]. However, other materials, such as zinc oxide and eugenol cements [37] and photo-activated glass ionomer [38] have already been described.

\section{Calcium hydroxide}

Historically, $\mathrm{CH}$ has been described as the most used material for direct pulp capping procedures. It was introduced in dentistry in 1921 by Hermann and for several decades it was considered the "gold standard" of capping materials [39,40]. Chemically, $\mathrm{CH}$ is a strong base with an alkaline $\mathrm{pH}$ of 12.5 to 12.8 . Its main action is based on ionic dissociation of the calcium $\left(\mathrm{Ca}^{+2}\right)$ and hydroxyl $\left(\mathrm{OH}^{-}\right)$ions, guaranteeing its high $\mathrm{pH}$ that gives it excellent antibacterial properties, minimizing or eliminating the penetration of microorganisms and subsequent irritation of the pulp tissue, in addition to helping maintain the state of alkalinity of the exposed pulp tissue. These properties are essential to enable tissue formation $[41,42]$.

When in contact with the exposed pulp tissue the CH induces a chemical injury caused by hydroxyl ions, causing an initial superficial necrosis [43]. This necrosis causes mild irritation and stimulates the pulp to repair, forming a dentin bridge of reparative dentin as result of cell differentiation, extracellular matrix secretion and subsequent mineralization by saturation of the zone with calcium ions [42,44-46]. However, studies have reported that the mineralized tissue barrier formed is discontinuous, of poor quality, and irregular requiring a long time for its formation, which enables microorganism's invasion and complications of the tissue repair $[47,48]$. In fact, $\mathrm{CH}$ has several disadvantages, such as inflammation of the pulp surface, which may present necrosis after capping, presence of tunnel defects in the dentin bridge, high solubility in oral fluids, lack of adhesion, degradation over time and, adding all these factors, the lack of an efficient seal of the underlying pulp against recurrent infections due to microleakage [49-51].

As a result of the disadvantages found in the use of $\mathrm{CH}$, a significant number of materials have been tested and reported in the literature in the last two decades as alternatives to $\mathrm{CH}$. These new classes of materials seem to have more promising results, justifying the return to the study of pulp capping materials by the endodontic community.

\section{Mineral Trioxide Aggregate (MTA)}

MTA was developed at the University of Loma (United States of America) and was first introduced in dentistry by Torabinejad in 1993, proposing a material for Para endodontic surgeries, with the main goal of promoting the sealing of communication between inside and outside environment. Nowadays, MTA is indicated in several clinical situations, for example: direct pulp capping, as endodontic cement, perforation repair, apical plugs for immature teeth and for coronary sealing after regenerative endodontic procedures [52]. MTA has been characterized as a bio stimulative or bioactive material, due to the fact that it promotes very favorable tissue reactions $[53,54]$. Bioactivity is a characteristic of a biomaterial to form mineral hydroxyapatite on its surface [55].

Chemically, the MTA consists of a powder (white or gray) composed of hydrophilic particles that, in the presence of water, solidify. This powder is formed by a mixture composed mainly of tricalcium silicate, tricalcium aluminate, tricalcium oxide, silicate oxide and bismuth oxide (which gives it radiopacity). Its handling consists of incorporation with distilled water, supplied by the manufacturers [56-58].

Its mechanism of action described in the literature is based on the principles that MTA forms $\mathrm{CH}$ that releases calcium ions, which favors cell adhesion and proliferation; creates an antibacterial environment by alkaline $\mathrm{pH}$; modulates cytokine production; encourages the differentiation and migration of cells that will form an extracellular matrix to be mineralized; and forms hydroxyapatite or carbonated apatite on the surface in contact with the MTA, providing a biological seal [59]. Still, other factors that seem to favor the repair are its excellent sealing capacity, which makes marginal infiltration difficult; low solubility; and satisfactory radiopacity $[53,54,60]$.

The literature has shown that pulp tissue responds favorably to MTA, with the deposition of a complete barrier of mineralized tissue, in a shorter formation time when compared to $\mathrm{CH}$, with a minimal sign of inflammation to the tissue, maintaining the remaining pulp with normal characteristics. In addition, the success rate of pulp therapies using MTA has been superior to techniques using $\mathrm{CH}$ materials [61,62]. However, the main disadvantages of MTA have been described as the high rate of coronary gray discoloration, difficulty in handling, its high cost and its long setting time, resulting in high solubility at an early stage, which can lead to microleakage [63-65]. 
Cavalcanti et al. [66] evaluated the effect of different pulpcapping materials on the secretion of interleukin-1 beta (IL-1 $\beta$ ) and interleukin-8 (IL-8) by migrating human neutrophils. They found that MTA caused significantly higher secretion of IL- $\beta$ than $\mathrm{CH}$. Then they concluded that in combination with all the other biological advantages of MTA described above, their results indicate that MTA could be considered the material of choice for dental pulp capping.

\section{Tricalcium silicate based cement (Biodentine)}

Biodentine (Septodont, Saint-Maur-des-Fosses, France) was launched in 2009 with the proposal of being a "dentine substitute" and has been frequently described in the literature as an extremely promising material, being the main representative of tricalcium silicate-based cements used in dentistry. The positive characteristics of Biodentine showed in the literature reviews are represented by its physical properties superior to those of other materials, better handling, excellent biocompatibility and a wide range of clinical applications, similar to those of MTA [67].

The material is available in the form of a capsule containing the ideal proportion of the powder for subsequent addition of the liquid. The powder composition is formed by tricalcium silicate, calcium carbonate and zirconium oxide (radio pacifier); while the liquid contains calcium chloride dihydrate, which acts as an accelerator, Areo and purified water. Both substances present in the liquid contribute to reduced setting times (from 10 to 12 minutes). In addition, the composition of the liquid accelerates the hydration reaction and reduces the amount of water needed for the mixture, providing adequate consistency, which also contributes to the easy handling of the mixture [68].

Biodentine is associated with a high pH (12) and the release of calcium and silicon ions, which stimulates mineralization and creates a "mineral infiltration zone" along its interface with dentin, providing a better seal. Caron et al. [69] found that Biodentine exhibits sealing properties superior to that of MTA. According to Rajasekharan et al. [70], as Biodentine overcomes the main disadvantages of MTA, it has great potential to revolutionize the different modalities of treatment in dentistry, especially after traumatic injuries. However, more long-term, high-quality clinical studies are needed for definitive conclusions. On the other hand, literature reviews and randomized clinical trials have shown that Biodentine and MTA show similar results in terms of success rates for either direct pulp capping or application after pulpotomy [7173].

Recently Petta et al. [74] evaluated the osteogenic differentiation of human dental pulp stem cells in response to substances released by the pulp capping agents, Biodentine (BD), mineral trioxide aggregate (MTA) and two-paste calcium hydroxide cement (CHC), along with their physicochemical characteristics. They showed that BD was the most stable material and formed the higher number of mineralized nodules even when non-mineralizing cell culture medium was used. They concluded that BD presents physicochemical characteristics more conducive to pulp repair than those of MTA and $\mathrm{CH}$.

\section{Success rates}

Although the Biodentine presents physical and biological chacteristics superior that those of $\mathrm{CH}$ and MTA, until now the success rates of these materials applied in clinical trials seems to be similar. Several studies in the literature have shown high success rates for pulp capping procedures, mainly through clinical and radiographic evaluations. Brizuela et al. [75] conducted a randomized clinical trial with permanent teeth with pulp exposure that were directly capped with $\mathrm{CH}$, MTA or Biodentine. Follow-up clinical evaluations were performed at 1 and 3 weeks, 6 months and 1 year. In one week, patients presented $100 \%$ clinical success rates in all groups. Over time, it was possible to notice a few failure cases (especially in the $\mathrm{CH}$ group). There was no statistical difference between the materials.

Katge [76] compared the direct pulp capping procedure in the young pulp of permanent molars through clinical and radiographic evaluation. The selected patients had bilateral first molars with caries involvement. According to the split mouth design, patients were divided into Biodentine (right side) and MTA (left side) groups as capping materials. The evaluations after 6 and 12 months reported a $100 \%$ success rate for both materials used at both periods.

Parinyaprom et al. [77] also compared the success rates of direct pulp capping using MTA and Biodentine in permanent teeth with pulp exposure after 6 months, using clinical and radiographic evaluations to determine success. They found a success rate of 92.6\% for MTA and $96.4 \%$ for Biodentine, with no significant difference. Gray discoloration was present in 55\% of teeth capped with MTA. In the Biodentine group, no discoloration was observed.

\section{Conclusion}

The re-emergence of vital pulp therapies gained strength in dentistry, especially due to its biologically minimally invasive approach. Direct pulp capping, when well indicated, seems to be an effective alternative capable of maintaining the health and vitality of the dentin-pulp complex. Recently, the development of new biocompatible materials, such as MTA and Biodentine, has being related with high rates of clinical and radiographic success for this treatment. However more randomized clinical trials are still needed to assess the quality of this treatment in the long term. In addition, histomorphological analysis of the newformed hard tissue and adjacent pulp tissue would also be helpful to understand the predictability of the prognosis.

\section{References}

1. Pashley DH (1996) Dynamics of the pulpo-dentin complex. Crit Rev Oral Biol Med 7(2): 104-133.

2. Goldberg M, Kulkarni AB, Young M, Boskey A (2011) Dentin: structure, composition and mineralization. Front Biosci (Elite Ed) 3: 711-735.

3. Machado MEL (2017) Endodontia ciência e tecnologia. Quitessence Publishing, São Paulo, Brasil.

4. Smith AJ (2002) Pulpal responses to caries and dental repair. Caries Res 36(4): 223-232. 
5. Huang GT (2011) Dental pulp and dentin tissue engineering and regeneration: advancement and challenge. Front Biosci (Elite Ed). 3: 788-800.

6. Smith AJ, Smith JG, Shelton RM, Cooper PR (2012) Harnessing the natural regenerative potential of the dental pulp. Dent Clin North Am 56(3): 589-601.

7. Bleicher F (2014) Odontoblast physiology. Exp Cell Res 325(2): 65-71.

8. Kuttler Y (1959) Classification of dentine into primary, secondary, and tertiary. Oral Surg Oral Med Oral Pathol 12(8): 996-999.

9. Cooper PR, Takahashi Y, Graham LW, Simon S, Imazato S, et al. (2010) Inflammation- regeneration interplay in the dentine-pulp complex. J Dent 38(9): 687-697.

10. Bjørndal L (2008) The caries process and its effect on the pulp: the science is changing and so is our understanding. J Endod 34(7 Suppl): S2-S5.

11. Smith AJ, Cassidy N, Perry H, Bègue Kirn C, Ruch JV, et al. (1995) Reactionary dentinogenesis. Int J Dev Biol 39(1): 273-280.

12. Bjørndal L, Darvann T (1999) A light microscopic study of odontoblastic and non- odontoblastic cells involved in tertiary dentinogenesis in welldefined cavitated carious lesions. Caries Res 33(1): 50-60.

13. Sloan AJ, Smith AJ (2007) Stem cells and the dental pulp: potential roles in dentine regeneration and repair. Oral Dis 13(2): 151-157.

14. Tziafas D, Kodonas K (2010) Differentiation potential of dental papilla, dental pulp, and apical papilla progenitor cells. J Endod 36(5): 781-789.

15. Smith AJ, Duncan HF, Diogenes A, Simon S, Cooper PR (2016) Exploiting the bioactive properties of the dentin-pulp complex in regenerative endodontics. J Endod 42(1): 47-56.

16. Goldberg M, Farges JC, Lacerda Pinheiro S, Six N, Jegat N, et al. (2008) Inflammatory and immunological aspects of dental pulp repair Pharmacol Res 58(2): 137-147.

17. Komabayashi T, Zhu Q (2010) Innovative endodontic therapy for antiinflammatory direct pulp capping of permanent teeth with a mature apex. Oral Surg Oral Med Oral Pathol Oral Radiol Endod 109(5): e75-81.

18. Bjørndal L, Simon S, Tomson PL, Duncan HF (2019) Management of deep caries and the exposed pulp. Int Endod J 52(7): 949-973.

19. Téclès O, Laurent P, Zygouritsas S, Burger AS, Camps J, et al. (2005) Activation of human dental pulp progenitor/stem cells in response to odontoblast injury. Arch Oral Biol 50(2): 103-108.

20. Chogle SM, Goodis HE, Kinaia BM (2012) Pulpal and periradicular response to caries: current management and regenerative options. Dent Clin North Am 56(3): 521-536.

21. Cohenca N, Paranjpe A, Berg J (2013) Vital pulp therapy. Dent Clin North Am 57(1): 59-73.

22. Wei X, Ling JQ (2019) [Contemporary concept and clinical perspective of direct pulp capping therapy]. Zhonghua Kou Qiang Yi Xue Za Zhi 54(9): 577-583.

23. Hargreaves KM, Diogenes A, Teixeira FB (2013) Treatment options: biological basis of regenerative endodontic procedures. J Endod 39(3 Suppl): S30-S43.

24. Komabayashi T, Zhu Q, Eberhart R, Imai Y (2016) Current status of direct pulp-capping materials for permanent teeth. Dent Mater J 35(1): 1-12.

25. Bergenholtz G, Mjör IA, Cotton WR, Hanks CT, Kim S, et al. (1985) The biology of dentin and pulp. Consensus report. J Dent Res 64 Spec No: 631-633.

26. Couve E (1986) Ultrastructural changes during the life cycle of human odontoblasts. Arch Oral Biol 31(10): 643-651.
27. Aguilar P, Linsuwanont P (2011) Vital pulp therapy in vital permanent teeth with cariously exposed pulp: a systematic review. J Endod 37(5): 581-587.

28. Zander HA, Glass RL (2005) The healing of phenolized pulp exposures. 1949. Oral Surg Oral Med Oral Pathol Oral Radiol Endod 100(2 Suppl): S97-101.

29. Bergenholtz G (2005) Advances since the paper by Zander and Glass (1949) on the pursuit of healing methods for pulpal exposures: historical perspectives. Oral Surg Oral Med Oral Pathol Oral Radiol Endod 100(2 Suppl): S102-108.

30. Cho SY, Seo DG, Lee SJ, Lee J, Lee SJ, et al. (2013) Prognostic factors for clinical outcomes according to time after direct pulp capping. J Endod 39(3): 327- 331.

31. Lipski M, Nowicka A, Kot K, Postek Stefańska L, Wysoczańska Jankowicz I, et al. (2018) Factors affecting the outcomes of direct pulp capping using Biodentine. Clin Oral Investig 22(5): 2021-2029.

32. Dammaschke T (2008) The history of direct pulp capping. J Hist Dent 56(1): 9- 23.

33. Alex G (2018) Direct and indirect pulp capping: A brief history, material innovations, and clinical case report. Compend Contin Educ Dent 39(3): 182-189.

34. Tjäderhane L (2002) The mechanism of pulpal wound healing. Aust Endod J 28(2): 68-74.

35. Modena KC, Casas Apayaco LC, Atta MT, Costa CA, Hebling J, et al. (2009) Cytotoxicity and biocompatibility of direct and indirect pulp capping materials. J Appl Oral Sci 17(6): 544-554.

36. Ferracane JL, Cooper PR, Smith AJ (2010) Can interaction of materials with the dentin-pulp complex contribute to dentin regeneration? Odontology 98(1): 2-14.

37. Holland R, Mello W, Souza V, Nery MJ, Bernabé PF, et al. (1981) The influence of the sealing material in the healing process of inflammed pulps capped with calcium hydroxide or zinc oxide-eugenol cement. Acta Odontol Pediatr 2(1): 5-9.

38. Felton DA, Cox CF, Odom M, Kanoy BE (1991) Pulpal response to chemically cured and experimental light-cured glass ionomer cavity liners. J Prosthet Dent 65(5): 704-712.

39. Baume LJ, Holz J (1981) Long term clinical assessment of direct pulp capping. Int Dent J 31(4): 251-260.

40. Hilton TJ (2009) Keys to clinical success with pulp capping: a review of the literature. Oper Dent 34(5): 615-625.

41. Barthel CR, Levin LG, Reisner HM, Trope M (1997) TNF-alpha release in monocytes after exposure to calcium hydroxide treated Escherichia coli LPS. Int Endod J 30(3): 155-159.

42. Farhad A, Mohammadi Z (2005) Calcium hydroxide: A review. Int Dent J 55(5): 293-301.

43. Pallotta RC, Machado MEL, Reis NS, Martins GHR, Nabeshima CK (2010) Tissue inflammatory response to the implantation of calcium hydroxide and iodoform in the back of rats. Revista Odonto Ciência 25(1): 59-64.

44. Holland R, de Souza V, de Mello W, Nery MJ, Bernabé PF, et al. (1979) Permeability of the hard tissue bridge formed after pulpotomy with calcium hydroxide: a histologic study. J Am Dent Assoc 99(3): 472-475.

45. Schröder U (1985) Effects of calcium hydroxide-containing pulpcapping agents on pulp cell migration, proliferation, and differentiation. J Dent Res 64: 541-548.

46. Mohammadi Z, Dummer PM (2011) Properties and applications of calcium hydroxide in endodontics and dental traumatology. Int Endod J 44(8): 697-730. 
47. Nair PN, Duncan HF, Pitt Ford TR, Luder HU (2008) Histological, ultrastructural and quantitative investigations on the response of healthy human pulps to experimental capping with mineral trioxide aggregate: A randomized controlled trial. Int Endod J 41(2): 128-150.

48. Brignardello PR (2019) Mineral trioxide aggregate may be superior to calcium hydroxide for histologic dentin bridge formation after pulp capping. J Am Dent Assoc 150(3): e29.

49. Cox CF, Sübay RK, Ostro E, Suzuki S, Suzuki SH (1996) Tunnel defects in dentin bridges: their formation following direct pulp capping. Oper Dent 21(1): 4-11.

50. Cox CF, Tarim B, Kopel H, Gürel G, Hafez A (2001) Technique sensitivity: biological factors contributing to clinical success with various restorative materials. Adv Dent Res 15: 85-90.

51. Kitasako Y, Ikeda M, Tagami J (2008) Pulpal responses to bacterial contamination following dentin bridging beneath hard-setting calcium hydroxide and self-etching adhesive resin system. Dent Traumatol 24(2): 201-206.

52. Tawil PZ, Duggan DJ, Galicia JC (2015) Mineral trioxide aggregate (MTA) its history, composition, and clinical applications. Compend Contin Educ Dent 36(4): 247-252.

53. Torabinejad M, Parirokh M (2010) Mineral trioxide aggregate: a comprehensive literature review--part II: leakage and biocompatibility investigations. J Endod 36(2): 190-202.

54. Parirokh M, Torabinejad M (2010a) Mineral trioxide aggregate: a comprehensive literature review--Part I: chemical, physical, and antibacterial properties. J Endod 36(1): 16-27.

55. Sanz JL, Rodríguez Lozano FJ, Llena C, Sauro S, Forner L (2019) Bioactivity of bioceramic materials used in the dentin-pulp complex therapy: A systematic review. Materials (Basel) 12(7): 1015.

56. Camilleri J, Montesin FE, Brady K, Sweeney R, Curtis RV, et al. (2005) The constitution of mineral trioxide aggregate. Dent Mater 21(4): 297-303.

57. Camilleri J (2008) The chemical composition of mineral trioxide aggregate. J Conserv Dent 11(4): 141-143.

58. Garcia A, Machado MEL, Britto MLB, Nabeshima CK, Massaro H (2011) Comparação qualitativa da constituição do cimento de Portland e MTAAngelus ${ }^{\circledR}$ através de difração de raios X. Revista do Instituto de Ciências da Saúde (UNIP) 29: 89- 91.

59. Parirokh M, Torabinejad M (2010b) Mineral trioxide aggregate: a comprehensive literature review--Part III: Clinical applications, drawbacks, and mechanism of action. J Endod 36(3): 400-413.

60. Roberts HW, Toth JM, Berzins DW, Charlton DG (2008) Mineral trioxide aggregate material use in endodontic treatment: a review of the literature. Dent Mater 24(2): 149-164.

61. Li Z, Cao L, Fan M, Xu Q (2015) Direct pulp capping with calcium hydroxide or mineral trioxide aggregate: A meta-analysis. J Endod 41(9): 1412-1417.

62. Paula AB, Laranjo M, Marto CM, Paulo S, Abrantes AM, et al. (2018) Direct pulp capping: What is the most effective therapy? Systematic review and meta-analysis. J Evid Based Dent Pract 18(4): 298-314.
63. Fridland M, Rosado R (2003) Mineral trioxide aggregate (MTA) solubility and porosity with different water-to-powder ratios. J Endod 29(12): 814-817.

64. Chiang TY, Ding SJ (2010) Comparative physicochemical and biocompatible properties of radiopaque dicalcium silicate cement and mineral trioxide aggregate. J Endod 36(10): 1683-1687.

65. Możyńska J, Metlerski M, Lipski M, Nowicka A (2017) Tooth discoloration induced by different calcium silicate-based cements: A systematic review of in vitro studies. J Endod 43(10): 1593-1601.

66. Cavalcanti BN, Rode Sde M, França CM, Marques MM (2011) Pulp capping materials exert an effect on the secretion of IL-1 $\beta$ and IL-8 by migrating human neutrophils. Braz Oral Res 25(1): 13-18.

67. Malkondu Ö, Karapinar Kazandağ M, Kazazoğlu E (2014) A review on biodentine, a contemporary dentine replacement and repair material. Biomed Res Int 2014: 160951.

68. Kaur M, Singh H, Dhillon JS, Batra M, Saini M (2017) MTA versus Biodentine: Review of literature with a comparative analysis. J Clin Diagn Res 11(8): ZG01- ZG05.

69. Caron G, Azérad J, Faure MO, Machtou P, Boucher Y (2014) Use of a new retrograde filling material (Biodentine) for endodontic surgery: two case reports. Int J Oral Sci 6(4): 250-253.

70. Rajasekharan S, Martens LC, Cauwels RGEC, Anthonappa RP (2018) Biodentine ${ }^{\mathrm{TM}}$ material characteristics and clinical applications: a 3 year literature review and update. Eur Arch Paediatr Dent 19(1): 1-22.

71. Awawdeh L, Al Qudah A, Hamouri H, Chakra RJ (2018) Outcomes of vital pulp therapy using mineral trioxide aggregate or biodentine: A prospective randomized clinical trial. J Endod 44(11): 1603-1609.

72. Mahmoud SH, El Negoly SA, Zaen El Din AM, El Zekrid MH, Grawish LM, et al. (2018) Biodentine versus mineral trioxide aggregate as a direct pulp capping material for human mature permanent teeth-A systematic review. J Conserv Dent 21(5): 466-473.

73. Tran XV, Salehi H, Truong MT, Sandra M, Sadoine J, et al. (2019) Reparative mineralized tissue characterization after direct pulp capping with calcium-silicate-based cements. Materials (Basel) 12(13): 2102.

74. Petta TM, Pedroni ACF, Saavedra DF, Faial KDCF, Marques MM, et al. (2020) The effect of three different pulp capping cements on mineralization of dental pulp stem cells. Dent Mater J 39(2): 222-228.

75. Brizuela C, Ormeño A, Cabrera C, Cabezas R, Silva CI, et al. (2017) Direct pulp capping with calcium hydroxide, mineral trioxide aggregate, and biodentine in permanent young teeth with caries: A randomized clinical trial. J Endod 43(11): 1776-1780.

76. Katge FA, Patil DP (2017) Comparative analysis of 2 calcium silicatebased cements (Biodentine and Mineral Trioxide Aggregate) as direct pulp-capping agent in young permanent molars: A split mouth study. J Endod 43(4): 507-513.

77. Parinyaprom N, Nirunsittirat A, Chuveera P, Na Lampang S, Srisuwan T, et al. (2018) Outcomes of direct pulp capping by using either proroot mineral trioxide aggregate or biodentine in permanent teeth with carious pulp exposure in 6- to 18-year-old patients: A randomized controlled trial. J Endod 44(3): 341-348. 